\title{
LOS «CANTOS DE MUJERES». NUEVAS PERSPECTIVAS*
}

\author{
Elvira Gangutia Elícegui \\ CSIC \\ elvira.gangutia@cchs.csic.es \\ «WOMEN SONGS». NEW PERSPECTIVES
}

\begin{abstract}
Intento de puesta al día, a partir de finales de los años noventa, de la cuestión de los «cantos de mujeres» en textos griegos antiguos y su reflejo en la poesía latina y posterior, con especial atención al «nuevo Safo» y algunos descubrimientos de textos latinos en la Península Ibérica.

Palabras clave: cantos mujer; novedades poesía griega arcaica; nuevo Safo; textos latinos Calagurris.
\end{abstract}

The question of «women songs» and their development in Latin poetry and after, revisited since the end of the 90's, with especial attention to the «New Sappho»; also to some Latin texts discovered in the Iberian Peninsula.

Keywords: women songs; novelties Greek archaic poetry; new Sappho; Latin texts Calagurris.

\section{Precedentes, Paralelos y temas destacables}

\section{Introducción}

Nuestra intención es estudiar en este trabajo las novedades producidas desde que publicamos nuestro Cantos de mujeres en Grecia ${ }^{1}$. Tomamos como referente cronológico y bibliográfico el año 2004 cuando la Fundación Lexis, con motivo del vigésimo aniversario de la publicación de la obra Actualiza-

* Una primera versión de este trabajo fue presentada en septiembre de 2008 en el Ciclo de Conferencias «Caminos de la literatura griega a la castellana (Madrid, 15-17 de septiembre de 2008)», organizado por la Fundación Duques de Soria y Lexis pro Diccionario Griego-Español. Agradecemos los comentarios, sugerencias bibliográficas, ayudas informáticas, etc., de P. A. García Pastor, E. Gil, R. Martínez Nieto, F. Pordomingo, H. y J. Rodríguez Somolinos.

1 E. Gangutia, Cantos de mujeres en Grecia, Madrid, 1994 (en adelante Cantos de mujeres; ver en pp. 129-175 la Antología de Cantos de Mujeres = ACM, abreviatura que se añadirá a pasajes citados la primera vez que se mencionan, indicando que fueron estudiados en Cantos de mujeres). 
ción científica en Filología griega, editada por Alfonso Martínez (Madrid, 1984), convocó a treinta y un profesores e investigadores a colaborar en un curso en el que se ponían al día los descubrimientos y estudios en nuestro ámbito en esos veinte años².

Los que llamamos «cantos de mujeres» están constituidos por diferentes formas de expresión del amor, desesperación, desafío, etc., en boca de mujer, o de una divinidad femenina. Hace ya años, nos llamó la atención, en los casi cien versos de Aristófanes, Ec. $877-975^{3}$ (= ACM 41), la semejanza de varios de los textos con algunas de las jarchas de la lírica medieval hispanoárabe y del género «de amigo» peninsular. Ello nos llevó a profundizar en la cuestión, descubriendo un tesoro de textos que afloran en la historia de la literatura desde épocas muy remotas, en el que los «cantos de mujer griegos» tendrían más peso del que se cree y notable influencia en el futuro. $\mathrm{Su}$ ámbito cronológico y geográfico es amplísimo, arrancando del Oriente Medio babilónico con una gran composición de esquema dialógico o dramático entre un hombre y una mujer, en el que ésta se queja del desvío del amado, manifestando el hombre cierto desdén y crudeza; finalmente parece producirse la reconciliación ${ }^{4}$.

${ }^{2}$ Veinte años de filología griega 1984-2004 (F. Rodríguez. Adrados, J. A. Berenguer, E. R. Luján y J. Rodríguez Somolinos [eds.]), Madrid, CSIC, 2008, obra en la que son particularmente útiles para nuestro trabajo: J. A. Berenguer, «Papirología», pp. 63-101; H. Rodríguez Somolinos, «Literatura arcaica», pp. 447-477; J. García López, «Literatura clásica», pp. 479502; E. Fernández-Galiano, «Literatura helenística», pp. 503-523.

${ }^{3}$ Las abreviaturas de autores y obras griegos son las mismas que las del Diccionario Griego Español I, «Lista I. Autores y obras», Madrid, CSIC, 2008², pp. LV-CXL; en casos particulares añadimos el nombre del editor (Voigt para Safo, para distinguir ciertos textos de los del «nuevo Safo»), o lo variamos con respecto al DGE (M. Davies, Poetarum melicorum graecorum fragmenta, Oxford, 1991, por presentar algún fragmento más completo); para el Epodo de Colonia de Arquíloco y Anacreonte seguimos, respectivamente, R. Merkelbach y M. L. West, ZPE 14, 1974, pp. 97-113, y D. Page, Poetae melici graeci, Oxford, 1962 (por habernos basado en la presentación unitaria de ciertos textos, tal como aparecen en los papiros de los que proceden).

4 «Diálogo-disputa amoroso babilónico», trad. de E. Martínez Borobio, en Cantos de mujeres, pp. 130-135 (=ACM 1). 


\section{El peso de la épica}

Éramos escépticos en nuestros primeros trabajos ${ }^{5}$ sobre indicios en la épica homérica del género que nos ocupa. Sin embargo, ahora pensamos que hay que explorar ese campo más sistemáticamente, a la vista de la abundancia de estudios en los últimos años sobre la lengua de la lírica griega, en la que se confirma el enorme peso de la tradición épica. El léxico se revela en gran parte el mismo, pero utilizado en forma diferente, a veces soterradamente alusivo, incluso irónico.

Creemos ahora que es posible descubrir en el propio Homero alusiones veladas al género de los «cantos de mujeres». Por ejemplo, en presencia de su recuperada e impasible esposa Helena, en $O d$. IV 271 ss. cuenta Menelao a Telémaco cómo aquélla, cuando todavía vivía con Paris, colaboraba con los troyanos hasta el punto de tratar de obligar a delatarse a los héroes griegos escondidos dentro del famoso caballo de Troya. En esa ocasión, Helena, en una especie de ritual mágico, da tres vueltas alrededor del caballo, a la vez que llama a los emboscados aqueos imitando las voces de las esposas de cada uno de ellos. Es decir, actúa como actriz y ventrílocua, rasgo este último que la acerca a la hechicería. Pero ¿en qué consisten esas llamadas? Es de suponer que eran en lengua griega pero, dado el ámbito asiático en el que se desarrolla esta acción de carácter pre-dramático, podrían ser algo semejante a las minúsculas frases documentadas en lidio, o en una lengua minorasiática, recopiladas por el lexicógrafo Hesiquio $(\beta 294,314, \imath 1204, \kappa 4180=$ $A C M 28 \mathrm{a}, \mathrm{b}, 29 \mathrm{a}, \mathrm{b}, \mathrm{c})$. La primera de ellas se ha encontrado incrustada en un poema papiráceo atribuido al jonio Hiponacte $(95=A C M 28 \mathrm{a})$ : $\eta \tilde{v} \delta \alpha$ $\delta \varepsilon \grave{\varepsilon} \lambda v \delta i \zeta \zeta o v \sigma \alpha$ ' $\beta \alpha ́ \sigma \kappa[\ldots] \kappa \rho о \lambda \varepsilon \alpha$ ' «dijo ella en lidio: “¡Ven (más) cerca!"». A continuación, en el texto hiponacteo, a pesar de lo roto del papiro, se entrevé una serie de obscenidades y frases escatológicas que constituyen un cómico conjuro para recuperar la virilidad. La grosería y la sal gorda, aunque pueden aparecer adyacentes, no son lo normal en el «canto de mujer», del que es más propio la ambigüedad y la insinuación, a veces con un carácter malicioso o irónico, cuando no desafiante.

Volviendo a Helena y sus eventuales cánticos-llamada. El resultado es un eficaz encantamiento: sólo la energía de Odiseo impide que los temibles guerreros aqueos se delaten y salgan del caballo-trampa. Esta tradición podría

\footnotetext{
5 Ver Cantos de mujeres, n. 2.
} 
explicar que, en época helenística, en Lyr. Alex. Adesp. 6 (=ACM 53) aparezca Helena quejándose de que su marido Menelao la tiene abandonada. En el pasaje, con versos de corte homérico, se inserta (vv. 8,9) un claro «canto de

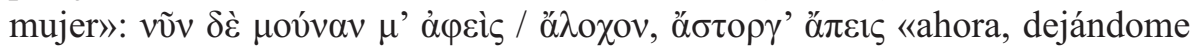
sola a mí, tu esposa, te marchas, cruel» ${ }^{6}$.

Los eventuales cantos de llamada de Helena en $O d$. IV 271 ss., como ya hemos recordado, se producen en Troya, es decir en Anatolia. Este ambiente híbrido greco-anatolio resulta útil para situar a Alcmán, quien, según testimonios antiguos, era lidio, instalándose posteriormente en Esparta. Sus solemnes peanes y otros variados fragmentos permiten atisbar actividades socio-religiosas de sus protagonistas, las $\pi \alpha \rho \sigma \varepsilon ́ v o l$, las «doncellas» espartanas. En Cantos de mujeres, pp. 12 ss. y 138-142 (= ACM 3a-f), teníamos en cuenta varios maltrechos fragmentos (4a.1, p. 47; S5b.I, II, pp. 67-68 Davies) que confirmarían que Alcmán compuso para fiestas de mujeres que «saltaban» o se «bañaban» en un río, lo que fue relacionado por nosotros con poemas atribuidos a nuestro poeta con el título de Ko $\lambda v \mu \beta \tilde{\omega} \sigma \alpha l$ 'Las que saltan al agua'. Estas muchachas hacen votos por llegar a celebrar sus bodas y acertar en el matrimonio (S5b.II.16-18, p. 68 Davies); ante ellas parece que llega un hombre, cuya presencia es evidente en otros versos (S5b.I.9, II.13, pp. 67-68 Davies). Por otro lado, en un escolio a Od. VI 244, al comentar

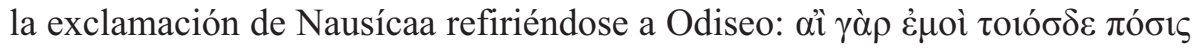

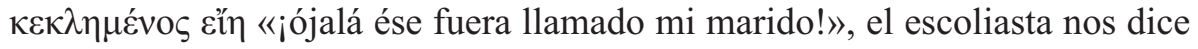

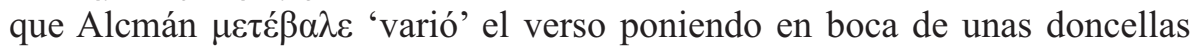

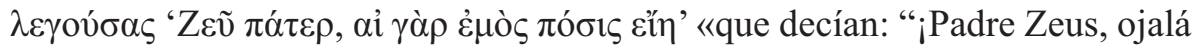
fuera mi marido!"» (Alcm. 81 Davies $=A C M 3 \mathrm{c})^{7}$. Pensamos que esta línea podría proceder de algún poema semejante a los arriba mencionados, en los que muchachas que celebran un rito lustral expresan honestos deseos de matrimonio, incluso preferencias, que luego serán mal vistas: al escoliasta del pasaje odiseico le parecen las palabras de Nausícaa impropias de una donce-

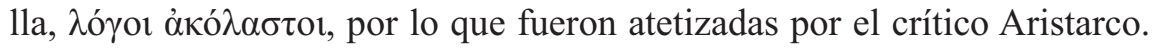

${ }^{6}$ De hecho, este poema forma parte de un conjunto antológico o, tal vez, un programa para ser ejecutado en el banquete, recogido en $P$. Teb. 1.1, 2, papiro en el que se encuentran otras composiciones que participan de rasgos de los «cantos de mujer», como el llamado Anonymum Tebtunites (Mim. Fr. Pap. 2 = ACM 52); cf. F. Pordomingo, «Les anthologies du P. Teb. I.1 et 2», en G. Bastianini, M. Manfredi y G. Menci (eds.), Atti del XXII Congresso Internazionale di Papirologia (Firenze, 23-29 Agosto 1998), Florencia, 2001, pp. 1077-1093.

${ }^{7}$ Cf. Cantos de mujeres, p. 12 ss. 
Ahora podemos añadir otro fragmento de Alcmán (11.35.I.25, p. 60 Davies, procedente de un comentario en $P$. Oxy. 2389) en el que se lee la curiosa

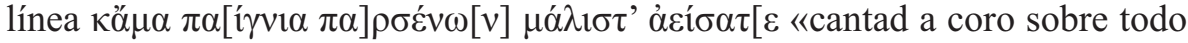
los juegos de las doncellas». Tal vez estos juegos consistían en música y canto acompañando a algún tipo de acción o ejercicio físico, como el «salto al agua» que se entrevé en estos fragmentos, o la enigmática carrera del gran peán 1.50 Davies, con paralelismo en $O d$. VI 96 ss. en el baño en el mar y juego de pelota ${ }^{8}$ acompañado de $\mu \mathrm{o} \lambda \pi \eta ́$ de Nausícaa y sus compañeras, ante las que también en un momento dado se presenta un hombre, Odiseo. El sueño premonitorio de Nausícaa en relación con la llegada del tiempo del matrimonio precedería a la escena en forma discretamente alusiva (Od. VI 27).

Sigamos con Homero y su influencia sobre estas particulares formas de la lírica. En nuestros trabajos primerizos sobre el tema decíamos que las quejas de Penélope por su marido ausente tenían en la Odisea una contención demasiado severa para lo que representa el género de los «cantos de mujer». Así, cuando Penélope en $O d$. XX 61-65 pronuncia una serie de versos desesperados por la ausencia de su esposo, la queja es de carácter épico, sobrehumano y particularmente desmesurado: «Ojalá ... arrebatándome una ráfaga,

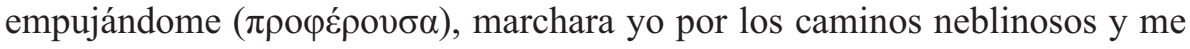
arrojara en la desembocadura del Océano refluyente».

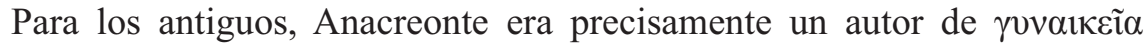
$\mu \varepsilon ́ \lambda \eta$, según el testimonio extraordinario y antiguo de Critias, Eleg. 8, quien

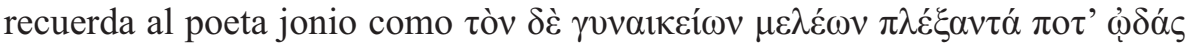
«el que trenzaba cantos de mujeres». Y, efectivamente, nos han quedado varios ejemplos de ellos (ver p. ej. ACM 20-27), siendo uno de los más interesantes para entender en qué consistía este «trenzar cantos de mujeres» el poema 2 Page (=ACM 24), en el que el poeta se queja del corte de pelo de un joven tracio: hacia el final, sin aparente nexo lógico, el autor, con una

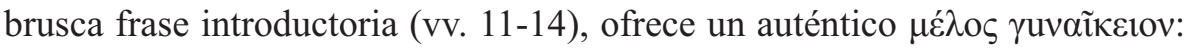

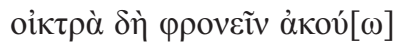

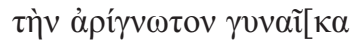

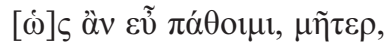

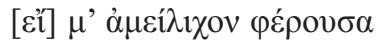

${ }^{8}$ Sobre el juego de pelota como símbolo de cultos eróticos, implicando una invitación al amor por parte de la mujer, v. F. Rodríguez Adrados, Sociedad, amor y poesía en la Grecia antigua, Madrid, 1995, p. 250, con bibliografía. 


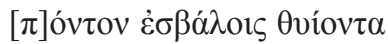

$[\pi] о \rho \varphi[v \rho] \varepsilon ́ o l \sigma l \kappa v ́ \mu \alpha \sigma \imath$

Oigo las cosas lastimeras que piensa esa mujer demasiado conocida, muchas veces dice esto acusando a la fatalidad: «ßBien lo pasaría, madre, si llevándome, me arrojaras al mar cuando se enfurece con olas purpúreas!».

Pensamos ahora que en estos versos subyace una solapada alusión a la exagerada queja épica de $O d$. XX 63: la ráfaga que Penélope desea que, llevándola en volandas $(\pi \rho \circ \varphi \varepsilon ́ \rho o v \sigma \alpha)$, la arroje a las bocas del Océano se convierte en el poema anacreonteo en la madre a la que, un tanto absurdamente, su hija suplica que la lleve ( $\varphi \varepsilon ́ \rho o v \sigma \alpha)$ hasta arrojarla a un mar borrascoso.

En los versos siguientes del citado testimonio de Critias, Eleg. 8, puede observarse dónde y cómo se actualizaba el «trenzar cantos de mujeres» de

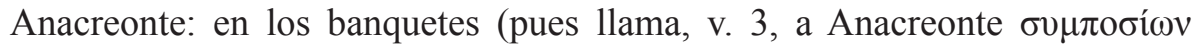

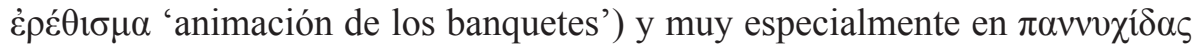

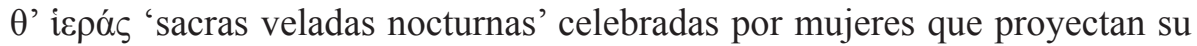

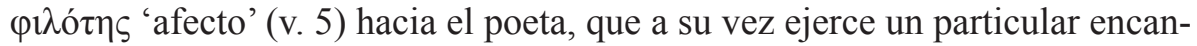

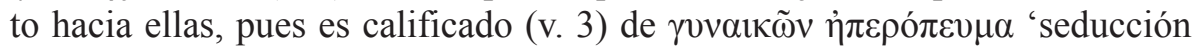
de las mujeres'. Las diferencias no son tantas con Alcmán: cantos de mujeres en fiestas, relación de afecto y seducción entre el coro y el poeta, que no envejecerá ni morirá mientras su fama se actualice en esas fiestas.

\section{El nUevo PAPIRO DE SAFO}

\section{Papiros con textos líricos de consideración}

Durante unos años, un considerable y casi incesante número de hallazgos hizo que Page publicara el Supplementum lyricis graecis, Oxford, 1974, pero el descubrimiento del Epodo de Colonia, atribuido a Arquíloco (Merkelbach-West), obligó a abrir un Appendix al final de la obra, en la que tampoco pudieron incluirse el papiro de Lille de Estesícoro (222b Davies) o alguno de los de Alcmán antes mencionados. Tras estos tiempos de actividad, se produce una época de «relativo sosiego» ${ }^{9}$ a no ser por el excelente texto de Simónides (fr. 1a Gentili-Prato, 2. ${ }^{\mathrm{a}}$ ed.). La situación ha cambiado espec-

\footnotetext{
9 Rodríguez Somolinos, «Literatura de época arcaica», p. 457.
} 
tacularmente en 2004, justo al final del ciclo que se cerraba con el simposio «Veinte años de filología griega». Procedente de los extraordinarios fondos de los papiros de Oxirrinco, se publica el $P$. Oxy. 4708, atribuido a Arquíloco, que hemos leído con gran interés en la esperanza de encontrar algo que pudiera ser relacionado con el magnífico Epodo de Colonia mencionado, del que nos habíamos ocupado en diferentes ocasiones ${ }^{10}$. Pero el nuevo texto consiste en una elegía homerizante, muy interesante, pero que no afecta al género que ahora nos ocupa.

En el mismo año, procedente como tantas otras veces de Mummienkartonnage, Michael Gronewald y Robert W. Daniel ofrecen con el título «Ein neuer Sappho Papyrus» en ZPE 147, 2004, pp. 1-8, la primicia de unos papiros (P. Köln inv. 21351 frs. I, II e inv. 21376, transcritos en el s. III a. C.). En ellos se entrevé inicialmente un texto conocido como de Safo, aunque en su conjunto ofrecen y ofrecerán interrogantes que, aún hoy, están lejos de haber sido resueltos.

\section{Fases previas a la edición crítica del «nuevo Safo»}

El largo y laborioso proceso de la publicación de este texto ha hecho que muchos sabios filólogos hayan entrado en liza, por lo que no hay más remedio que esbozar la secuencia bibliográfica de este fenómeno filológico de importancia capital, no sólo para el género que nos ocupa, sino para el conocimiento de la poesía griega en general, tanto temática como compositivamente. Teniendo en cuenta que, en el momento de la primicia, los editores numeran ${ }^{11}$ correlativamente los versos de los dos fragmentos, se descubre, por un lado, que los vv. 9-20 coinciden y completan los vv. 11-22 del fragmento Sapph. 58 Voigt (=ACM 10), basado en P. Oxy. 1787 (transcrito en el s. III d. C.), y reconocido como sáfico porque al final aparecen dos versos

10 «La poesía griega "de amigo" y los recientes hallazgos de Arquíloco», Emerita 45, 1977, pp. 1-6; Cantos de mujeres, p. 9 ss.; ver ahora A. Nicolosi, Ipponatte, Epodi di Strasburgo. Archiloco, Epodi di Colonna (con un appendice su P. Oxy. LXIX 4708), Eikasmos. Studi 14, Bolonia, 2007, con amplia y útil bibliografía; cf. también Líricos griegos. Elegíacos y yambógrafos arcaicos (siglos VII-V a. C.), ed. y trad. de F. Rodríguez Adrados, Madrid, $2010^{4}$, p. 328 ss.

${ }^{11}$ La forma de citar estos textos se ha ido convirtiendo en algo cada vez más complejo, por lo que por ahora llamaremos al conjunto papiráceo «nuevo Safo», hasta el momento en que sean editados como P. Köln 429, 430. 
autorizados como de la poetisa por Clearco 41. Pero ahí acaban las coincidencias, en cualquier caso notables si tenemos en cuenta el tiempo transcurrido entre una y otra copia o versión. En el papiro recientemente hallado, en lugar del final testimoniado por Clearco para 58 Voigt, aparece un texto totalmente diferente, que los autores confiesan que en ese momento no se encuentran en situación de editar salvo en algunas palabras, sobre las que apenas aventuran una interpretación. Los versos iniciales 1-8 del «nuevo Safo» tampoco tienen nada que ver con los versos 1-10 que encabezaban el fr. 58 Voigt.

En el mismo año 2004, los editores Gronewald y Daniel ofrecen en «Nachtrag zum neuen Sappho Papyrus», ZPE 149, pp. 1-4, lecturas clarificantes y comentadas a los dos pedazos papiráceos procedentes de P. Köln inv. 21376 que completan las líneas 16 a 20 del fr. II. Además, en la fotografía puede apreciarse con claridad la primera línea del texto que en el nuevo papiro aparece en lugar del final que conocíamos por 58 Voigt. Los editores leen aquí

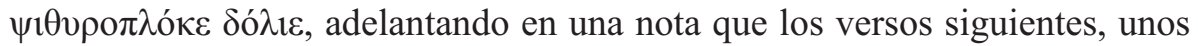
trece, serán publicados en la colección de los Kölner Papyri (Papyrologica Coloniense) una vez suficientemente estudiados. Confesamos que la lectura de esa minúscula línea nos produjo enorme interés, porque pensamos que la explicación podría estar en alguno de los «cantos de mujeres» que habíamos venido estudiando desde el año 1972.

El texto había llamado extraordinariamente la atención de M. L. West: en «The new Sappho», ZPE 151, 2005, pp. 1-9, dice esperar «with eager interest» (p. 1) la edición de las líneas que faltan. En lo que se refiere al cuerpo del poema, se dedica a («with some difficulty», p. 2) «diseñar suplementos» o conjeturas que puedan soldar los frs. I y II del texto papiráceo, después de haber vuelto a estudiar con microscopio algunos minúsculos restos de $P$. Oxy. 1787, editado por Lobel y que sirvió de base para 58 Voigt. El resultado es la restauración, con indudable conocimiento, de un «poema completo», conclusión que muy fina y atinadamente, como siempre, matizará Di Benedetto en «La nuova Saffo e dintorni», ZPE 153, 2005, pp. 7-20. Efectivamente, el poema reconstruido por West queda demasiado redondo, acabado y recortado: en lo referente al abrupto e incómodo final de 58.25-26 Voigt, editado a partir de Clearco $41+P$. Oxy. 1787, dictamina West «we now recognize to be the beginning of another poem» (p. 7).

Pero ya en el número siguiente de $Z P E(152,2005)$ empieza a haber filólogos que dudan de que, con la laboriosa reconstrucción de West, el «new Sappho» quede atado y bien atado. Aunque todavía el texto no había sido 
editado en su totalidad, se hacía evidente que debían ser replanteados muchos aspectos. Puede observarse una vuelta a cuestiones, incluso globales, de la poesía de Safo, como su formación literaria y musical, en relación a la situación geográfica y cultural de Lesbos en el ámbito anatolio, Lidia, o el Próximo Oriente, como focos culturales ${ }^{12}$.

\section{Temas que cobran relieve creciente}

\section{a) Juventud opuesta a decrepitud y muerte}

La ausencia en el «nuevo Safo» de los versos finales del fr. 58 Voigt resulta tan sorprendente que, en el momento en el que todavía no había sido desvelado en qué consistía el texto substitutorio en el «nuevo Safo», provoca gran número de renovados estudios sobre el anterior final. Creemos importante, por lo tanto, dedicar cierta atención al tema.

En el verso 19 del texto resultante de la unión de P. Köln inv. 21351 frs. I, II + P. Köln inv. 21376, ensamblado y complementado a su vez con $P$. Oxy. 1787 (= Sapph. 58 Voigt), la poetisa se ocupaba del mito de Titono raptado por la Aurora, quien consiguió de los dioses para este muchacho la inmortalidad, pero olvidó pedir para él la juventud eterna. Hasta ahora, a partir de la palabra ö́oıııv 'esposa', aparecían en 58 Voigt cuatro versos (23-26) de los que los dos últimos, como hemos recordado, nos eran conocidos como de Safo y pronunciados por ella según Clearco 41: curiosamente, este autor helenístico aristotélico era parcialmente coetáneo de la época en que se copia el «nuevo Safo», en el que sin embargo no aparece su testimonio, materializado nada menos que quinientos años más tarde en $P$. $O x y .1787$ para ser editado en el fr. 58 Voigt sáfico.

12 A. Hardie, «Sappho, the Muses, and Life after Death», ZPE 152, 2005, pp. 13-32, estudia instituciones del canto femenino profesionalizado relacionándolas con grupos análogos del mundo hetita, Asiria y Egipto; también señala que en Mitilene y Éreso se han encontrado huellas de culto arcaico a divinidades anatolias como Cibele, diosa con culto en Locros y censada como plañidera con un $\mu$ غ́̇o $\varsigma$ por su hijo/amante en Mim. Fr. Pap. App. 8.10-15 (ACM 54): ver Gangutia, Cantos de mujeres, p. 22, y nn. 30, 63, e íd., «Notas interpretativas y paralelos a PLit. Lond. 51 (Cantus lugubris 10 Heitsch, Fragmenta mimorum papyracea, Appendix 8 Cunningham)», en Miscelânea em honra da Dra. Maria Helena da Rocha Pereira, Humanitas 47, 1995, p. 482 y nn. 1, 3. 
Nuestra traducción a estos versos (fr. 58.25-26 Voigt) era en Cantos de mujeres, p. 145: «Pero yo amo la lozanía ... eso y a mí el brillante amor del Sol y lo bello me corresponden», basándonos en que es la Aurora la que, de manera desafiante, reclama las atribuciones que como diosa le 'corresponden' $\left(\lambda \varepsilon ́ \lambda \sigma \gamma \chi \varepsilon^{13}\right)$, es decir, la lozanía de la juventud y la belleza, así como la luz o el amor del Sol, viéndose sin embargo condenada a ocuparse de un ser cada vez más decrépito. Pero es Safo la que, identificada con la diosa, resistiéndose a los crueles efectos de la vejez pronunciaría esos dos últimos versos, como testimonia Clearco.

Gracias a la densa bibliografía existente actualmente tanto sobre 58 Voigt como sobre el «nuevo Safo» se evidencia que, junto a la belleza, la juventud y la lozanía, aparece casi como preceptivo el contrapunto de la decadencia física, la vejez. A partir del v. 13 del texto unificado (58 Voigt $+P$. Köln fr. II) comienza el tema de los «estragos de la edad» ${ }^{14}$ : ya en 58 Voigt, la poetisa habla de sus $\gamma o ́ v \alpha$ 'rodillas' que ya no la llevan, y sabemos ahora por P. Köln inv. 21351 II que esas piernas son calificadas de $\lambda \alpha i$ in $\rho$ ' 'ágiles' para bailar como las cabritillas. A estos versos Gronewald y Danie ${ }^{15}$ diligentemente descubren un excelente paralelo homérico, justamente en Il. XVIII 567 ss., pasaje en el que Homero presenta dos coros de muchachos y doncellas, en medio los cuales un $\pi \alpha$ ĩ 'muchacho' tañe la fórminge entonando el "canto

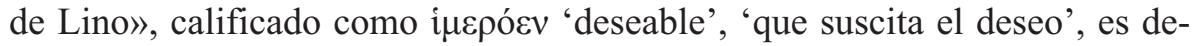
cir, también es canto de amor. Los coros acompañan con el canto y también danzan con «piernas saltarinas». Sin embargo, los editores olvidan señalar

${ }^{13}$ Con un claro precedente en la épica, esta vez hesiódica, Th. 201 ss., versos en los que se explicita cuales son las atribuciones $(\lambda \varepsilon \dot{\lambda} \mathrm{\gamma} \chi \chi \varepsilon)$ de Afrodita respecto a las muchachas jóvenes. Cf. V. Benedetto, «Il tetrastico di Saffo e tre postille», ZPE 155, 2006, pp. 5-18.

${ }^{14}$ Cantos de mujeres, pp. 28, 46 y 62. El tema de la vejez y la muerte paliada por la poesía en el «nuevo Safo» ha provocado gran número de publicaciones: señalamos aquí H. Bernsdorff, «Schwermut des Alters im neuen Kölner Sappho-Papyrus», ZPE 150, 2004, pp. 27-35; Hardie, «Sappho, the Muses, and Life after Death», pp. 13-32; H. Rodríguez Somolinos, «Safo, Titono y la cigarra ( $P$. Köln inv. 21351 re $+21376+P$. Oxy. 1787)», Ad amicam amicissime scripta. Homenaje a la profesora M. ${ }^{a}$ José López de Ayala, Madrid, 2005, I, pp. 129-136; íd., «Los nuevos versos de Safo y el tema de la inmortalidad por la poesía (P. Köln inv. 2135re.1.1-8)», en E. Calderón, A. Morales y M. Valverde (eds.), Koinós lógos. Homenaje al profesor José García López, Murcia, 2006, II, pp. 897-903; E. Livrea, «La vecchiaia su papiro: Saffo, Simonide, Callimaco, Cercida», en G. Bastianini y A. Casanova (eds.), I papiri di Saffo e di Alceo. Atti del Convegno Internazionale di studi, Firenze, 8-9 giugno, Florencia, 2007, p. 67 ss.

15 «Ein neuer Sappho-Papyrus», p. 7. 
que esta escena juvenil homérica es una de las más antiguas menciones de la lírica ${ }^{16}$ y que, además del «canto de Lino», género poético en el que según la tradición se insertaba la propia Safo, ella cantó a otros efímeros mancebos y semidioses como Faón o Adonis. Faón es una figura «especular» de Titono ${ }^{17}$ : si éste va haciéndose inmortalmente viejo, Faón, de feo y decrépito barquero de Lesbos, por obra y gracia de Afrodita, disfrazada de Vieja, se convierte en joven irresistible para las mujeres. La identidad de ambos, Titono y Faón, es tal que, si ahora gracias al «nuevo Safo» sabemos que Titono era calificado

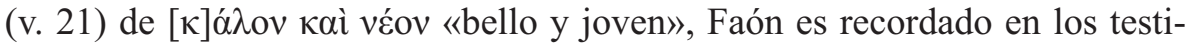

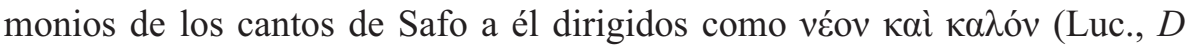

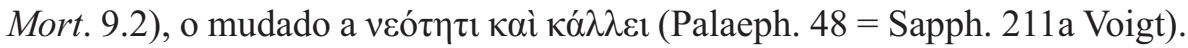
Estos cantos de Safo a Faón, en los que la poetisa tal vez se identificaba con una divinidad femenina amante, Afrodita, serán interpretados en la posteridad como una historia humana de amores desgraciados.

En el «nuevo Safo», unificado con 58 Voigt, se hacen más relevantes los signos de envejecimiento como el encanecimiento del cabello o los miembros debilitados, apareciendo la oposición «vejez»//〈juventud» como elemento casi preceptivo, o rasgo «biográfico» recurrente también en Alcmán (26 Davies) o Anacreonte (73, 75 Page): ellos también recuerdan cuando en sus buenos tiempos actuaban junto a coros de jóvenes, igual que el $\pi \alpha \tilde{\varsigma} \varsigma$ del texto homérico lideraba la fiesta con sus habilidades poético-musicales y danzarinas; sin embargo, a partir de determinado momento la decrepitud les impide hacerlo ${ }^{18}$. En relación con esto, Danielewicz ha aportado un paralelo importante proce-

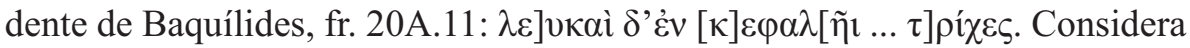
Danielewicz, entre otras alternativas, que puede ser que quien pronuncia este verso, introducido por i $i[\varepsilon] \tau \varepsilon v ́ \varepsilon ı$ en v. 6 , es Marpesa ${ }^{19}$, encerrada por su

${ }^{16}$ F. Rodríguez Adrados, en varias obras: Orígenes de la lírica griega, Madrid, 1976, pp. 85, 88; Lírica griega arcaica, Madrid, 1980, p. 11; «Lírica griega», en J. A. López Férez (ed.), Historia de la literatura griega, Madrid, 1988, p. 109; Sociedad, amor y poesía en la Grecia antigua, p. 131 ss. La tradición hará finalmente de Lino un poeta mítico, ver A. Bernabé (ed.), Poetae epici graeci, Berlín-Nueva York, 2007, II 3, pp. 56-104.

${ }_{17}$ Livrea, «La vecchiaia su papiro...», p. 71.

${ }^{18}$ Los versos con el tema de los «estragos de la edad» podían ser dirigidos también a una mujer a modo de «canto de escarnio», cf. Arquíloco, vv. 36-40 Merkelbach-West; Cantos de mujeres pp. 10, 62 y lo comentado a propósito de Anacreonte.

19 J. Danielewicz, «Bacchylides fr. 20a, 12 S.-M. and Sappho, P. Köln fr. I-II, 12», ZPE 155, 2006, pp. 19-21: compartimos el asombro del autor ante el hecho de que tal paralelo o imitación de Safo no hubiera sido advertido antes por otros filólogos. 
cruel padre, lo que nos hace pensar que estos versos bien podrían aludir a un «canto de mujer» que se queja de que llegará a la ancianidad sin posibilidad de casamiento. Hay otros elementos que aparecen en nuestro "género», como la queja por la soledad, $\mu$ ov́vๆ $v$ de v. 11, con paralelos importantes en $\mu$ óv $\alpha$

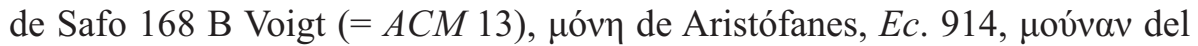

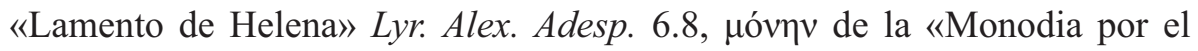
gladiador» Mim. Fr. Pap. 9.4 (= ACM 55), por no hablar de la $\mu \varepsilon \mu о v \omega \mu \varepsilon ́ v \eta$ del Fragmentum Grenfellianum, Mim. Fr. Pap. 1.26 (y cf. 35) (= ACM 52).

Hay un paso más: la muerte. En el verso 6 del «preámbulo» del «nuevo Safo» se dice ṽ̃v $\theta \alpha \lambda[i] \alpha$ «ahora es la fiesta»; casi inmediatamente en el verso siguiente parece que se habla de alguien que yace o yacerá «bajo tierra» vép $\theta \varepsilon \delta \dot{\varepsilon} \gamma \tilde{\alpha} \varsigma^{20}$. Pensamos que también en el «preámbulo» de 58.7 Voigt

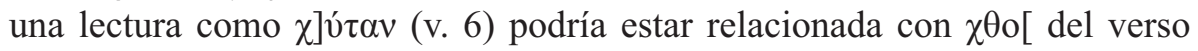
siguiente, haciendo referencia a la «tierra amontonada» de una tumba (cf.

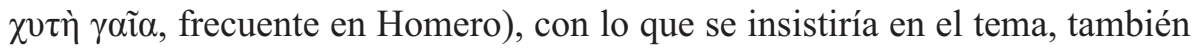
casi preceptivo, de la supervivencia del/la poeta gracias a la permanencia de sus cantos en el ritual y la fiesta: como dice de Anacreonte Critias, Eleg. 8.5, 8: «su fama no envejecerá ni morirá ... mientras coros femeninos celebren sacras veladas nocturnas»; también en el caso de Safo: mientras exista la fiesta ritual y se canten sus versos sobrevivirá a la muerte.

\section{b) Juventud, luminosidad y el amor de las diosas por bellos jóvenes y semidioses}

Entre los pocos datos que se han conservado de la formación de Safo, que, afortunadamente, está volviendo a ser estudiada ahora con más amplitud, se encuentra la mención del poeta Пó $\mu \varphi \omega s$, cuyo nombre significa el 'Todo luz'.

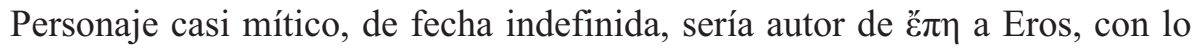
que se le equipara a Orfeo, según Pausanias 9.27.2 y 29.8 (=214 Voigt). Esta tradición de un mítico maestro luminoso habría tenido su máximo exponente

${ }^{20}$ En Arquíloco v. 8 Merkelbach-West, junto a la curiosa invocación a la doncella por su matronímico se recuerda el dato ¿írónico? de la muerte de la madre ìv võv $\gamma \tilde{\eta} \kappa \alpha \tau$ ' $\varepsilon$ inv. $21351+21376$ and P. Oxy. 1787 fr. 1: Music, cultural politics and hellenistic antholo-

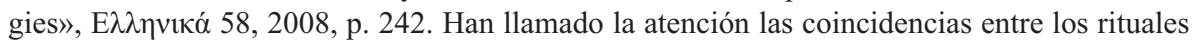
nupciales y los funerarios: R. Rehm, Marriage to death. The conflation of wedding and funeral rituals in Greek Tragedy, Princeton, Nueva York, 1994. 
en 58.26 Voigt, cuando la Aurora ${ }^{21}$, representada por la poetisa y desesperada por el irreversible envejecimiento de Titono, reivindica ع̌ $\rho \omega \varsigma$ à $\lambda \lambda$ íov el 'amor del Sol' o 'por el Sol', como su «parte asignada» en el mundo de los dioses. Y, además, Safo cantó a Faón (también el «Luminoso»), el que gracias a Afrodita neutralizó en sí «vejez»/〈juventud». Ello evidencia que debemos prestar mayor atención al componente 'luminoso' de la tradición en la que se inserta la poetisa.

Afortunadamente, contamos ahora con otros paralelos en los que el Sol y su luz pueden estar claramente identificados con el amado ${ }^{22}$. El llamado por Heitsch Cantus Lugubris, actualmente más legible en Mim. Fr. Pap. App. 8 (=ACM 54), es un texto revelador aunque pésimamente escrito en el siglo II d. C. En este poema, una diosa, cuyo nombre ignoramos ${ }^{23}$, ruega a otras que han pasado por el mismo trance ser instruida sobre cómo hacer el planto por la muerte o desaparición del hijo (¿o amante?). Esas diosas plañideras son: Clímene, que lloró a su hijo Faetón o Faetonte (cuyo nombre significa también el «Resplandeciente»); Cíbele, que lo hizo por su hijo y amado Atis;

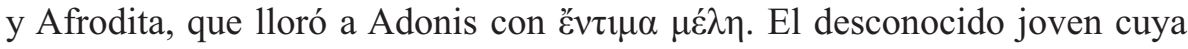

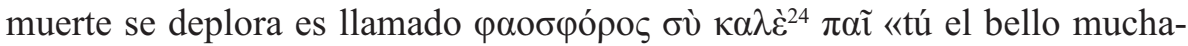

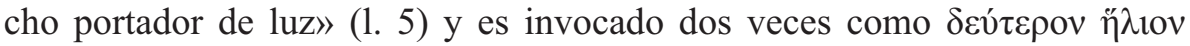
'segundo Sol' (vv. 9, 25).

Estas expresiones de intensas relaciones afectivas entre seres de una esfera luminosa ${ }^{25}$, aparecerán en relación con Safo no sólo en los versos finales de 58 Voigt, sino en posición hasta cierto punto paralela también al final del «nuevo Safo».

${ }^{21}$ Cf. también Safo 102, 123, 157 Voigt.

${ }^{22}$ Ver actualmente Livrea, «La vecchiaia su papiro...», que aduce buenos paralelos a esta traducción, desde la épica a Iul., Or. 11.1, incluida la literatura italiana, pp. 70-71.

${ }^{23}$ En Gangutia, «Notas interpretativas y paralelos a PLit. Lond. 51 ...», p. 483, opinábamos que podría tratarse de un planto de la Aurora, aunque aquí tal vez no por Titono sino por su hijo Memnón.

${ }^{24}$ Escrito $\kappa \alpha \lambda \varepsilon 1$.

${ }^{25}$ Cf. Cantos de mujeres, p. 22 ss.; «Notas interpretativas y paralelos a PLit. Lond. 51...», pp. $483-484$. 


\section{LA EDICIÓN COMPLETA DEL NUEVO PAPIRO DE SAFO}

\section{Los versos finales del «nuevo Safo»}

Llegamos al momento en que se editan en primicia los enigmáticos versos que Gronewald y Daniel dejaban entrever inmediatamente al final del citado «Nachtrag zum neuen Sappho Papyrus». Casi dos años más tarde, en $Z P E$, 154, 2005, pp. 7-12, los editores se consideraban en situación de sacar a la luz trece versos más con el título de Lyrischer Text (Sappho-Papyrus). Se trata de un texto de métrica y dialecto poco claros: el comienzo parece ático, pero luego vienen formas que podrían ser tanto eolias como dorias. En cuanto al contenido, los editores proponen que podría tratarse de un texto «dramático», con un o una interlocutora que se dirige en vocativo a un Knabe, un 'muchacho' y a un Freund, un 'amigo'; hay alguien que se marcha; se invoca la luz de las estrellas y del Sol resplandeciente; un personaje masculino dice $\pi \tilde{\alpha} \varsigma \dot{\alpha} \kappa o v ́ \omega$ «soy todo oídos»; se mencionan Orfeo y las fieras; un personaje femenino parece que toma la lira, etc.

Después de esta primicia del texto colocado al final del nuevo papiro de Safo, la perplejidad ha sido grande y durante un tiempo apenas ha habido menciones ni comentarios, extendiéndose hasta cierto punto un silencio ominoso o auténtico apagón filológico, también en el caso de West.

Es R. Rawles ${ }^{26}$ de los primeros que se ocupa de las enigmáticas líneas del colofón al final del «nuevo Safo», llamándole la atención los curiosos signos de puntuación, los numerosos dicola que interpreta como marcas para señalar la entrada de un intérprete diferente en un canto de tipo antifonal.

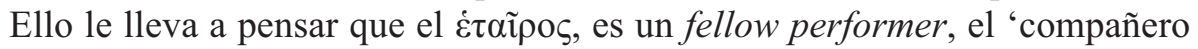
de reparto' en la interpretación, y diferente del $\pi \alpha$ ĩ . Cree que el inicio del poema es una dedicatoria hímnica, probablemente a una deidad, pensando que el carácter engañoso del personaje recuerda al habilidoso Hermes del himno a él dedicado. Particularmente interesante nos parece el trabajo de Liberman $^{27}$, quien constata cómo el fr. 58 Voigt y el «nuevo Safo» se complementan en un solo poema central, y, si el primero estaba enmarcado por

${ }^{26}$ En ZPE, 157, 2006, tras unas «Notes on the interpretation of the "New Sappho"», pp. 1-7 y luego en forma totalmente separada (pp. 8-13), con el título de «Musical notes on the New Anonymous Lyric Poem from Köln».

${ }^{27}$ G. Liberman, «L'édition alexandrine de Sappho», en Bastianini y Casanova (eds.), I papiri di Saffo..., p. 50 ss. 
«poemas» de la propia poetisa al principio y al final, el «nuevo Safo» está enmarcado por arriba por otro poema, considerado sáfico y métricamente idéntico, pero por abajo por una composición «anonyme dans une langue et un metre non éoliens».

\section{De P. Köln inv. $21351+21376$ a P. Köln 429 Sappho (2 Gedichte)} + P. Köln 430 Lyrischer Text

Pasarán todavía dos años más hasta que en 2007 se editen por fin los textos del «nuevo Safo» en la publicación seriada de los papiros de Colonia, Kölner Papyri (P. Köln.) 11, por obra de M. Gronewald y R. W. Daniel. Se trata de una edición sobria en cuanto a suplementos y conjeturas, cauta y sin comprometerse, acompañada de serios comentarios textuales y filológicos.

A partir de este momento, $P$. Köln inv. $21351+21376$ queda canónicamente llamado P. Köln 429 Sappho, pero constituido por dos poemas independientes (Gedichte 1,2), numerados el primero del verso 1 al $11 \mathrm{y} \mathrm{el}$ segundo del 1-12. Las misteriosas líneas del final reciben ahora la denominación de $P$. Köln 430 Lyrischer Text, un «texto lírico» que, parece, no debe ser considerado de Safo. A pesar de estas particiones (creo que, por lo menos, debiera haberse numerado entre paréntesis el conjunto del texto papiráceo) los ahora $P$. Köln 429 y 430 permiten por fin una visión de conjunto cómoda del extraordinario material poético del «nuevo Safo».

Nuestra idea es que el ahora denominado P. Köln 430 es una forma de poesia drammatica ${ }^{28}$, en forma de diálogo convencional, que contendría un «canto» del tipo de los que estudiábamos en Cantos de mujeres, introducido al final de un poema, en forma parecida a Anacreonte 2 Page. Según nuestra interpretación, quien habla en vv. 1 a 3 hasta $\dot{\tau} \tau \alpha i ̃ \rho \varepsilon$ es una mujer burlada que dirige reproches a su huidizo amante:

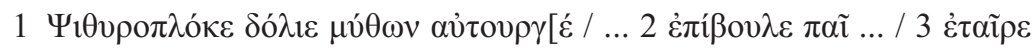

(Mujer) ¡Tramador de maledicencia, engañador, artífice de cuentos, ... muchacho insidioso ..., amigo!

${ }^{28}$ Expresión que tomamos de B. Gentili, Anacreon, Roma, 1858, p. XVI ss.; cf. Cantos de mujeres, pp. 33, 63 y n. 51. 
Si bien los editores reseñan una apabullante bibliografía para $P$. Köln $429^{29}$, es muchísimo más escasa la dedicada a $P$. Köln 430 Lyrischer Text ${ }^{30}$. Básicamente, los paralelos se refieren al Fragmentum Grenfellianum (Mim. Fr. Pap. 1), en el que una mujer abandonada suplica a su huido amante y le dirige rebuscados reproches, como el raro $\varphi \rho \varepsilon v \alpha \pi \alpha ́ \tau \eta \varsigma^{\prime}$ 'embaucador de la mente'.

Pero hay otros paralelos reveladores y anteriores a esta palabra y al conjunto

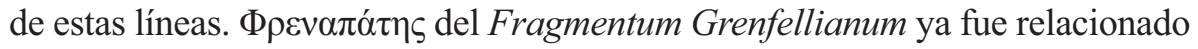
por nosotros en Cantos de mujeres, p. 76, con $\psi$ í $\theta v \rho{ }^{31}$ del fragmento papiráceo 19 (=ACM32) de Baquílides, con el interés añadido de aparecer unido a la

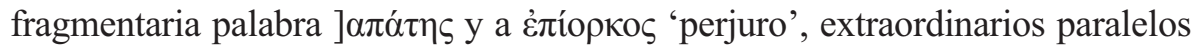
a los reproches de la mujer despechada de P. Köln 430.2. Enmarcando esos términos, al principio y al final se repiten en Baquílides fr. 19 dos versos que nos eran conocidos por Hefestión, Poëm. 7.3, como del lírico de Ceos y como

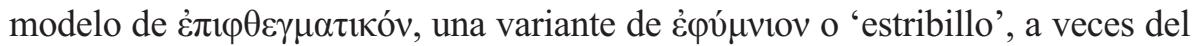
tamaño de una estrofa, que se adosa «a la estrofa propia de un poeta», tal como se reconstruye en el papiro (B. fr. $19=$ P. Oxy. $2361+$ Heph., Poëm. 73):

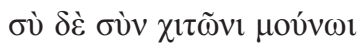

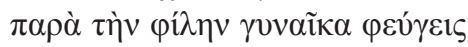

] $\mu \alpha \chi_{\alpha \alpha 1 \zeta}$

${ }^{29}$ En la que lamentablemente faltan casi totalmente títulos españoles, solamente un trabajo de Méndez Dosuna en la revista Mnemosyne 60, 2007, en ese momento todavía inédito; pero cf. supra nn. 2, 14.

${ }^{30}$ Remite solamente a cuatro artículos ya citados antes para $P$. Köln 429 y al libro de E. Esposito, Il fragmentum Grenfellianum (P. Dryton 50), Bolonia, 2006. E. Puglia, «Appunti sul nuovo testo lirico di Colonia», ZPE 164, 2008, p. 60, compara $P$. Köln 430 con el «Lamento de Helena», Lyr. Alex. Adesp. 6, mencionado aquí desde el principio.

${ }^{31}$ Esposito, Il fragmentum Grenfellianum, ha relacionado el cúmulo de reproches iniciales de $P$. Köln 430, además de con el texto objeto de su estudio, con B. fr. 19: vid. pp. 62, 123 y cf. 101, 105; también se fija en el pasaje de Baquílides M. Magnani, «Note alla nova Saffo»,

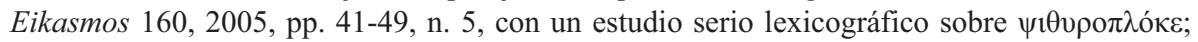
ofrece también una visión abierta sobre «finales» aparentemente definidos: una corónide no significa «fin assoluto» sino transición de un «componimento» a otro en determinado contexto papiráceo (p. 41, n. 2); también sobre el problema de los confini, limiti, en el «nuevo Safo», ver J. Lundon, «Il nuovo testo lirico nel nuovo papiro di Saffo», en Bastianini y Casanova (eds.), I papiri di Saffo..., pp. 151-152, cf. 155 ss., 166, no excluyendo totalmente la autoría de Safo para el «final» del nuevo $P$. Köln, observando puntos de contacto entre el cúmulo de vocativos del principio de P. Köln 430 y el de la oda 1.1-2 Voigt de Safo. 
$\dot{\varepsilon} \pi]$ íoркоs.

] $\alpha \pi \alpha ́[\tau \eta \zeta] \kappa \alpha i ̀ ~ \psi i ́ \theta v[\rho o \varsigma]$

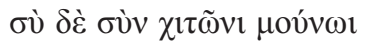

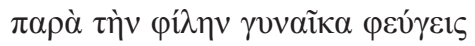

... engañador (?) y murmurador ... perjuro.

Tú, con el quitón sólo, escapas junto a tu querida mujer...

Tenemos aquí un primer modelo en el que se acumulan reproches de mujer, incluyéndolos entre estribillos que son, a la vez, «cantos de mujer». Todo ello nos hace pensar que B. fr. 19 (y 20A, relacionado este último por Danielewicz con el «nuevo Safo») pueden pertenecer o estar en la línea de un «género» similar.

Volviendo a P. Köln 430.2: las invectivas van dirigidas a un 'muchacho', 'mozo', $\pi \alpha \tilde{i}$ en vocativo ${ }^{32}$, tras el que viene un texto corrupto y lacuna,

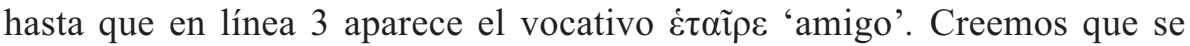
trata del mismo personaje: el 'amigo' como 'amante' de una mujer puede encontrarse en infinitos poemas y cantigas hispánicos «de amigo» que se va o viene al alba, abandona a la mujer, etc. Y que está también en la Grecia antigua con el mismo sentido en Semónides 8.49 y, sobre todo, en el extraordinario canto alternado entre la Muchacha y la Vieja de Aristófanes, Ec. 911-914: «¡Ay, ay, que más sufriré! No viene mi amigo ( $\mu$ oṽ $\alpha \iota \rho \circ \varsigma$ ), sola sin él me quedo» ${ }^{33}$.

Por lo tanto creemos que en $P$. Köln 430.3 cambia la persona y es el $\pi \alpha \tilde{i} \varsigma /$

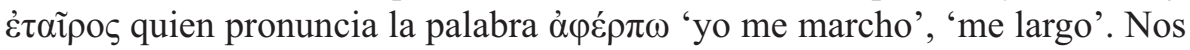
basamos para esta interpretación en uno de los mejores paralelos de este tipo de diálogo amoroso convencional, el llamado Marissaeum melos (Lyr. Alex. Adesp. $5=A C M 49 \mathrm{a}$ ), escrito en una tumba pintada de Marissa, lugar entre Jerusalén y Gaza. En este poema drammatico, que diría Gentili, una mujer recita cuatro versos desafiantes que traducimos: «No tengo que sufrir por ti

32 Паĩ como el 'amado' se encuentra en Sapph. 95 Voigt; también (voc.) en la «Monodia por el gladiador» (Mim. Fr. Pap. 9.9, cf. 6) y es el llorado «segundo Sol» del Mim. Fr. Pap. App. 8.9. Sin embargo, en otras monodias femeninas helenísticas, como el Fragmentum Grenfellianum o el Anonymum Tebtunites (respectivamente Mim. Fr. Pap. 1 y 2), el vocativo

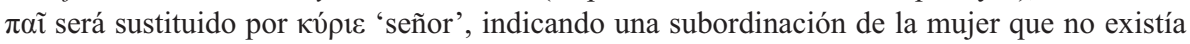
en las desafiantes diosas y mujeres de poemas anteriores.

${ }^{33}$ Ver Cantos de mujeres, pp. 90-91 y n. 169, y ACM 41.912. 
ni concederte favores. Y hasta duermo con otro, tanto te quiero. Pero, por Afrodita, mucho me alegro de que tu manto me queda en prenda $\rangle^{34}$. A estas

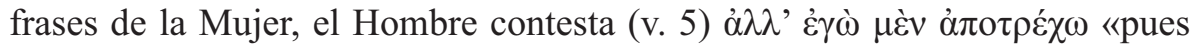

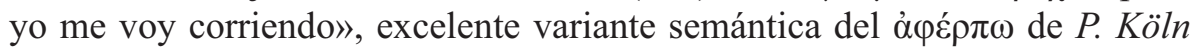
$430.3^{35}$.

Prosiguiendo con $P$. Köln 430: tras $\dot{\alpha} \varphi \hat{\varepsilon} \rho \pi \omega$ falta texto en las líneas 3 y 4 , en las que pensamos que la Mujer, ante la presunta huida del seductor, expresaría sus sufrimientos, de los que äjvvovs (1. 5) sería un resto, con el significado 'estoy sin aliento', 'sin respiración', es decir, 'prácticamente muerta',

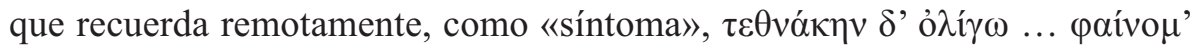
de Safo 31.15-16. Seguidamente, en $P$. Köln 430.6-8, la Mujer invocaría «la luz de los astros y el resplandor del Sol que brilla como el fuego». Entramos aquí en el tema de los astros, el Sol y lo luminoso, tan llamativo en los textos que nos ocupan, para el que no faltan paralelos: de Safo, al final de 58 Voigt y también 168B Voigt, (= $A C M 13)$, donde la poetisa manifiesta cómo sufre en soledad mientras pasan la Luna y los astros. También está la invocación a las estrellas y la noche de la Mujer del Fragmentum Grenfellianum (Mim.

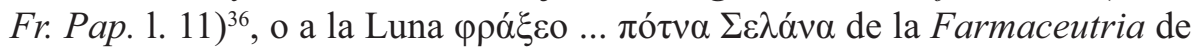
Teócrito 2 (=ACM 48b), a modo de estribillo repetido diez veces en un contexto en el que se realiza un encantamiento. Pero volvamos al Marissaeum melos (Lyr. Alex. Adesp. 5): al final (11. 7-8), la Mujer prohíbe al amante comunicarse con ella golpeando en la pared ${ }^{37}$, señal que posiblemente entraba dentro de una escala de favores en el código de galanteo: prefiere hacer ella otra señal, un $v \varepsilon \tilde{v} \mu \alpha$, desde un portillo. ¿En que consiste esta señal? Junto

34 Ver Cantos de mujeres, p. 114 ss. Estamos de acuerdo con Puglia, Appunti..., p. 13,

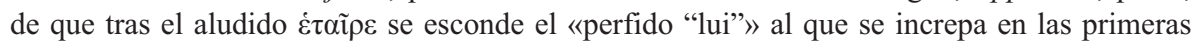
líneas de $P$. Köln 430.

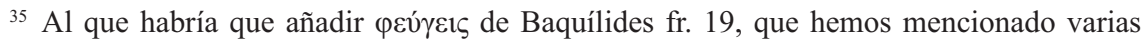

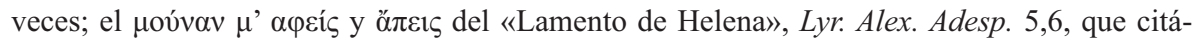

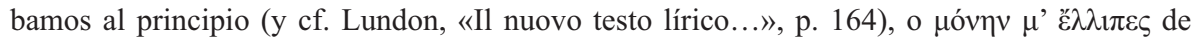
la «Monodia por el gladiador», Mim. Fr. Pap. 9.4; no hay que desdeñar la «virginidad» que $\dot{\pi}$ oí $\rceil ı$ en Sapph. 114 Voigt; el intento de detener la huida mortal del amado: de Adonis por

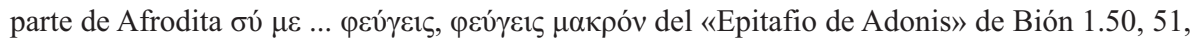
incluso mediante encantamiento, v. 95 (=ACM 50); del «segundo Sol» por la diosa plañidera

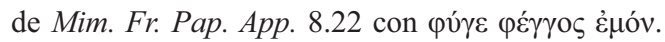

36 Recordada también por Esposito, Il fragmentum Grenfellianum, p. 111.

37 Favor ofrecido por la Joven en el Epodo de Colonia de Arquíloco v. 14 MerkelbachWest, que parece insuficiente al seductor. 
al Marissaeum melos ${ }^{38}$ se habían tomado en consideración dos pequeñas

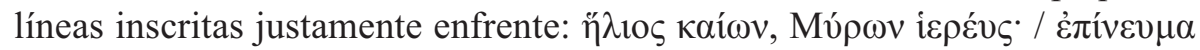

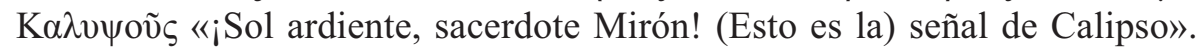
En Cantos de mujeres, pp. 115-118, n. 13, pp. 224-229, proponíamos que

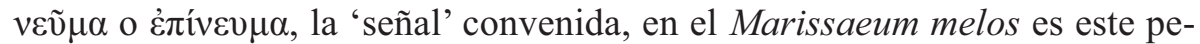
queño canto, dirigido a un personaje que, de alguna manera, es equiparado al Sol, insertándose en la lista de amados identificados con la esfera de lo

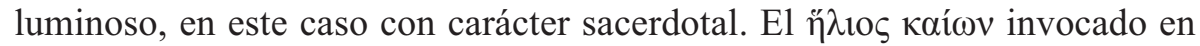
Marissa tiene paralelos en el «amor del Sol» del final de Safo 58 Voigt, en el $\pi \alpha$ invocado como «segundo Sol» de Mim. Fr. Pap. App. 8.19 y ahora en

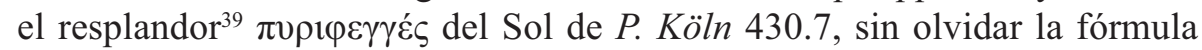

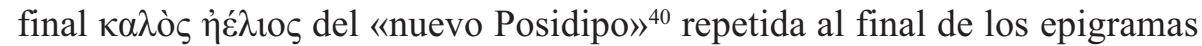
14, 16 y 52: en este último tras ser mencionada la vejez y la muerte.

En $P$. Köln 430.8 parece que alguien, al escuchar esos lamentos e invocaciones a los astros, dice $\pi \tilde{\alpha} \varsigma \alpha \dot{\alpha} \kappa o v \omega$ «soy todo oídos», primera persona verbal de la que un importante precedente está en las frases introductorias al «canto de mujer» al final de Anacreonte 2.11 Page, que mencionábamos al principio

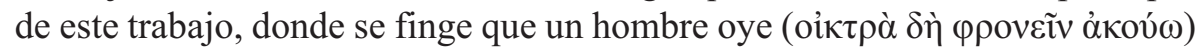
las cuitas de una vecina que confía a su madre su desesperación amorosa. Pensamos que en $P$. Köln 430.8 es el Muchacho ( $\pi \alpha \tilde{\text {, }}$, غ̇ $\alpha \tilde{i} \rho \varepsilon)$ el que escucha los lamentos, las invocaciones y los prolegómenos, también instrumentales, de un «canto de mujer»:

8-9 Oiór]

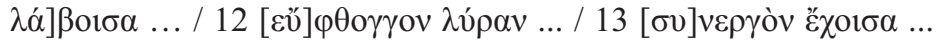

(Así como dicen) de Orfeo, el hijo de Eagro, que (amansaba) a todas las fieras, (yo), tomando la amable y biensonante lira y teniéndola como aliada, (entonaré un canto).

${ }^{38}$ Sobre la relación entre ambos textos, ya desde la edición de las inscripciones, por J. P. Peters y H. Thiersch, Painted tombs at Marissa, Londres, 1905, pp. 56-61, ver Cantos de mujeres, p. 114 ss. y n. 230. Últimamente ha vuelto a prestarse atención a este texto: ver en relación con nuestro trabajo J. Hordern, «An erotic inscription from Marisa, Judaea», ZPE 126, 1999, pp. 81-82.

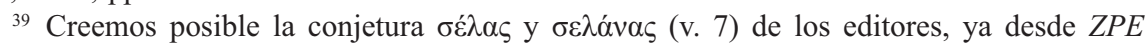
154, 2005, p. 11.

${ }^{40}$ C. Austin y G. Bastianini (eds.), Posidippi Pellaei quae supersunt, Milán, 2002. 
Este eventual canto se supone posiblemente irresistible para la reconciliación, con un léxico órfico con carácter próximo al encantamiento ${ }^{41}$ lo que no es ajeno a los «cantos de mujer» ${ }^{42}$.

Resumiendo: es difícil que el diálogo amoroso de $P$. Köln 430, colocado tras $P$. Köln 429, sea de Safo, pero su rebuscado léxico entra en lo poético, como señalan los editores en el comentario a $P$. Köln 430. Su autor, en cualquier caso, pretendió hacer una imitación de Safo, pues responde concretamente a contenidos de los dos Gedichte precedentes de P. Köln 429: la insistencia «introductoria» o de «preludio» del léxico relativo al instrumento

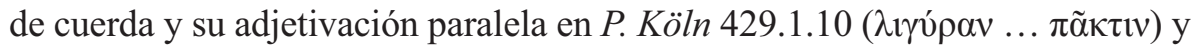

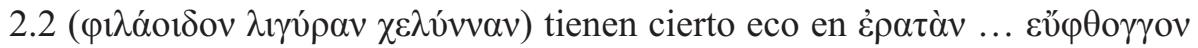
$\lambda u ́ \rho \alpha v$ de $P$. Köln 430.11-12. Dentro de esta línea imitativa, creemos un seguro

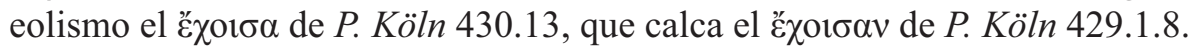
La insistencia, una vez más, en el ámbito solar, luminoso, que circunda el mito Aurora-Titono nos hace pensar que el eventual autor no desconocía el «otro final» de Safo 58.26 Voigt, en el que se habla del amor del Sol ${ }^{43}$.

\section{Partes o finales incongruos ${ }^{44}$}

Esto nos lleva a pensar que 58.23-26 Voigt y P. Köln 430 no son textos meramente yuxtapuestos en una secuencia antológica ${ }^{45}$, sino «finales» alternativos; pero también encontramos posiblemente «preámbulos» alternativos, dispuestos intencionadamente, como 58.1-10 Voigt y $P$. Köln 1.1-11. Es más:

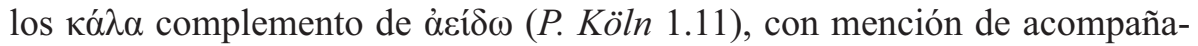
miento instrumental $\lambda ı \gamma v ́ \rho \alpha v ~ . . . \pi \tilde{\alpha} \kappa \tau \imath v$ de $P$. Köln 1.10, anticipan e introducen

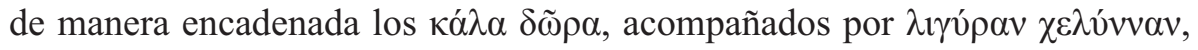

\footnotetext{
${ }^{41}$ R. Martínez Nieto, «P. Köln 430: una nota a la mención órfica en el Neue Sappho» (en prensa).

${ }^{42}$ Recordemos entre los aquí mencionados: Hippon. 95, el canto alternado entre la Joven y la Vieja en Ar., Ec. 906-910, la Farmaceutria de Theoc. 2, el intento de encantamiento para evitar la muerte de Adonis en Bion 1.95; ver Cantos de mujeres, esp. p. 110 ss.; cf. Puglia, Appunti..., p. 15 y n. 35 .

43 «Familiaridad» del «autor» de $P$. Köln 430 con la obra de Safo, según Yatromanolakis, «P. Colon. inv. $21351+21376$ and P. Oxy. 1787 fr. 1», p. 250.

${ }^{44}$ Ver Cantos de mujeres, p. 60 ss.

${ }^{45}$ Yatromanolakis, «P. Colon. inv. $21351+21376$ and P. Oxy. 1787 fr. 1», p. 254; en p. 245 se pregunta si no estaremos ante «performative versions of the same song».
} 
de los dos primeros versos de Sappho, $P$. Köln 2.1-2, pertenecientes al poema reconocidamente sáfico que como «centro» ${ }^{46}$ contiene el mito de la Aurora y Titono.

Hace tiempo que se han detectado composiciones griegas papiráceas de las que la tradición había señalado ciertas partes como de un autor conocido, pero con finales (y comienzos) «incongruos». Además de los versos finales de Safo 58.25-6 Voigt, atribuidos a la poetisa por Clearco 41, está el caso de otro gran papiro, el de Arquíloco Merkelbach-West, citado aquí varias veces, cuyos cinco versos finales (36-40) eran conocidos como del poeta de Paros por Hefestión, Metr. 15.847 fundamental es el dístico utilizado a modo de estribillo en Baquílides, fr. 19, autentificado también por Hefestión, Poëm. 7.3. Y no debemos olvidar los versos introducidos por frases de transición al final del poema de Anacreonte 2.11-18 Page. Ello nos hace pensar que quien puso por escrito en papiro el «nuevo Safo» lo consideraba hasta cierto punto como una unidad compositiva, siendo demasiado sencillo catalogar cada uno de estos «componentes» o «módulos» poéticos como poemas aislados y cerrados o self contained poems, recopilados en antologías ${ }^{48}$.

Acudimos a los epigramas del «nuevo Posidipo» para tratar de comprender algo más del «nuevo Safo»: Mario Puelma y Francesca Angiò recuerdan que en 2003, antes de que se descubriera el $P$. Köln sáfico, ya Di Benedetto ${ }^{49}$

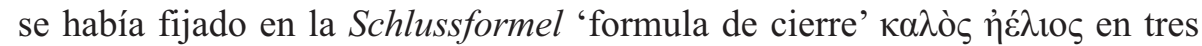
de los nuevos epigramas de Posidipo, relacionándolos con los famosos versos finales del poema 58 Voigt de Safo: en el epigrama 52 Austin-Bastianini del

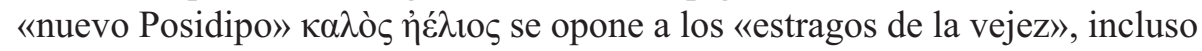
a la «muerte», temas que también aparecen en el poema de Safo y a los que ya nos hemos referido. También Bernsdorff en «Offene Gedichtschlüsse»o

46 Dentro del esquema compositivo de F. Rodríguez Adrados, Lírica griega arcaica..., p. 23, cf. íd., «Lírica griega», p. 111.

47 Ver también D. R. Slings, Some recently found Greek poems (supp. a Mnemosyne), Leiden-Nueva York-Copenhague-Colonia, 1987, pp. 62-63.

48 Género más complejo de lo que parece, ver F. Pordomingo, «Vers une caractérisation des anthologies sur papyrus», Akten des 23. internationale Papyrologen Kongresses (Wien, 22-28, Juli 2001), Viena, 2007, pp. 549-557: curiosamente, en esas antologías es rara la lírica y más la que nos ocupa.

49 M. Puelma y F. Angiò, «Sappho und Poseidippus», ZPE 152, 2005, pp. 13-15; V. Di Benedetto, «Omero, Saffo e Orazio e il novo Posidippo», Prometheus 29, 2003, p. 25, e íd. «La nuova Saffo e dintorni». 
«finales de poema abiertos» ${ }^{50}$, estudia esta posibilidad para el poema de Safo 58 Voigt, aduciendo numerosos paralelos, empezando por Alceo 44 y siguiendo por Píndaro, en el que, frecuentemente, tras un relato mítico que constituye un núcleo a modo de «centro», aparece como cierre una frase personal o sentenciosa ${ }^{51}$. Piensa también Di Benedetto ${ }^{52}$ que la afirmación de West de que el «new Sappho» recreado por él es un self contained poem resulta demasiado «axiomática», pues no sabemos nada de cómo se interpretaban los poemas de Safo, no digamos por ella misma. Estudia también eventuales moduli introduttivi de Safo, tan mal o peor conocidos que los finales eventualmente abiertos. También sugiere que no habría que negar la posibilidad de un scambio dialogico, cierta forma «convencional» drammatica, precisamente lo que se ha encontrado en el ahora denominado $P$. Köln 430.

Pensamos que estamos ante un «género» en el que se consideraba legítimo componer a base de partes o «módulos», iniciales y finales, con o sin versos introductorios, en estilo directo o dialogado, incluso insertados casi aleatoriamente en el cuerpo del poema, como es el caso del Epodo de Colonia de Arquíloco, vv. 17-19 Merkelbach-West o Alcmán 1.73-77 Davies; o repetido como estribillo en Baquílides, fr. 19, y denominado غ̇ $\pi \iota \varphi \theta \varepsilon \gamma \mu \alpha \tau \iota \kappa o ́ v$ por Hefestión, Роёm. 7.3.

Estos «módulos» o «componentes» podrían ser de un solo poeta o tomados de otro(s) diferente(s). En cualquier caso, parece que el resultado era considerado hasta cierto punto una suite unitaria. Aunque es difícil precisar todavía cómo se produce el proceso, el poeta o la poetisa podía tomarlos del continuum de la tradición para recrear una lírica con técnicas de versificación originalmente orales y en estrecha relación con la música ${ }^{53}$.

En los últimos años se ha trabajado bastante sobre las técnicas orales en la poesía lírica griega ${ }^{54}$. Existirían repertorios orales, de los que los poetas y los ejecutantes tomaban lo que les convenía según las circunstancias. El que aparezca al final de un poema algo parecido a un mimo en forma de

${ }^{50} \mathrm{H}$. Bernsdorff, «Offene Gedichtschlüsse», ZPE 153, 2005, pp. 1-6; aunque no muy convencido, Livrea, «La vecchiaia su papiro...», p. 69.

${ }^{51}$ Ver supra, n. 46.

52 Di Benedetto, «La nuova Saffo e dintorni».

${ }^{53}$ Ver Cantos de mujeres, p. 60 ss.

${ }^{54}$ Ver G. Nagy, Poetry as performance. Homer and beyond, Cambridge, 1996; cf. J. Signes, Escritura y literatura en la Grecia arcaica, Madrid, 2004, especialmente pp. 301-341; Yatromanolakis, «P. Colon. inv. $21351+21376$ and P. Oxy. 1787 fr. 1», p. 245 ss. 
diálogo-disputa amorosa convencional como $P$. Köln 430 tiene su sentido, muy especialmente en el banquete, en el marco del cual se está estudiando en los últimos años la composición oral en la lírica. Sin embargo, el que un poema de Safo lleve al final un tetrástico compuesto por ella misma, en el que se habla del «amor por el Sol», está dentro de una línea poética y musical relacionada con el culto y las fiestas femeninas, lo que puede rastrearse en otros poetas arcaicos como la propia Safo, Alcmán o Anacreonte.

El hecho de encontrarnos ante unos poemas cantados en el simposio, sometidos a reelaboración tanto por parte de los propios autores como de ejecutantes ajenos, ha provocado que algunos estudiosos piensen que es difícil restaurar con los métodos de la crítica textual tradicional la presentación de composiciones arcaicas aparecidas en papiros, imponiéndose la necesidad de replantear el formato de las ediciones de estos textos ${ }^{55}$. Y es indudable que la solución de partir los textos en self contained poems, que dispersan lo que en determinada época se consideró unido o digno de ser unido, no es la única y habrá que llegar a un tipo de edición que pueda resolver con sentido práctico (¿tal vez electrónicamente?) los problemas palpables y difíciles que revela la secuencia de publicaciones del «nuevo Safo», así como la de otros poemas.

\section{Caminos hacia el Medioevo}

\section{Textos latinos}

Aunque de forma más esquemática, debemos ahora ocuparnos de la eventual repercusión de las cuestiones tratadas en la literatura latina y romance.

¿Qué rutas permiten que géneros de protagonismo femenino, como los que se descubren en Safo y otros autores, reaparezcan por ejemplo en la Península Ibérica? En principio, está la tradición latina. Es sabido que Horacio recrea poemas sáficos enteros, con técnicas compositivas aparentemente

${ }^{55}$ Tras estudiar los casos de varias literaturas, se ha propuesto algún un tipo de edición multitextual, basándose Nagy (Poetry as performance, pp. 11-38) en la edición de R. Pickens (Toronto, 1978) del trovador provenzal Jaufré Rudel, quien reconocía que su obra no estaba en «pergaminos» sino en el canto; cf. Signes, Escritura y literatura, p. 337 y n. 100. Problemas de índole parecida se analizan en la edición del Corpus de la antigua lírica popular hispánica (siglos XV-XVII), Madrid, 1987, ed. por M. Frenk, quien (p. X) elige «una versión impresa» como texto base por «razones prácticas», pues «se trata de una poesía que se difunde oralmente», que «vive en variantes», teniendo por lo tanto «cada versión el mismo valor». 
similares $^{56}$, pero queremos aducir ahora a Nevio, quien en cum palliod unod ab amica abduxit (Pall. 36.3 Marmorale) recrea con intención satírica, 200 años después, una versión latina ${ }^{57}$ del fr. 19.2-3, 8-9 de Baquílides. Recordemos que estos dos versos del poeta de Ceos enmarcaban, repetidos a modo de

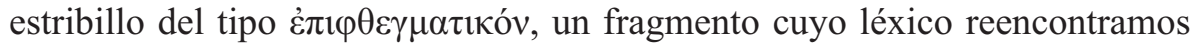
parcialmente en $P$. Köln 430.1. A su vez, este papiro fue escrito en época próxima a la de Nevio, procedente de Capua, de un entorno muy influido por la cultura griega.

De una tradición de protagonismo femenino provendrían las fiestas de doncellas que describe Ovidio en los Fasti 3.675-676 Frazer, tratando de explicar cur canent ... obscena puellae ... nam coueunt certaque probra canunt «por qué las jóvenes cantan» en fiestas de Marzo «canciones obscenas ... pues se reúnen y cantan ciertos cantos vergonzosos». Con estos versos Ovidio ofrece una de las explicaciones del mito de la vieja Anna Perenna, que engaña al dios Marte velada o disfrazada de joven novia (v. 690 tegens uoltus, ut noua nupta), convirtiéndose desde ese momento en una noua diua (v. 693), milagroso rejuvenecimiento femenino paralelo al mito de Faón ${ }^{58}$ : ello nos lleva de nuevo al canto de doncellas, teniendo como contrapunto una forma de ancianidad superable.

Hemos hablado antes de la tradición oral en relación con los «cantos de mujer ${ }^{59}$ y sobre ello volveremos. Pero hay otras vías y soportes, entre lo icónico y lo escrito, que pueden haber constituido una eficiente forma de difusión. Se trata de representaciones figuradas especialmente en vasos cerámicos, en los que aparecen personajes cantando. Uno de los paralelos aducidos por Gronewald y Daniel a la línea sobre el «brillo de los astros, el resplandor del Sol», etc., de P. Köln 430.6-7, es el poema de Praxila $1^{60}$

56 Bernsdorff, «Offene Gedichtschlüsse», p. 2 ss. El «nuevo Safo» ha provocado una revisión de la repercusión de la poetisa en los autores latinos: ver, en I papiri di Saffo e di Alceo, sobre Horacio: Liberman, «L'édition alexandrine de Sappho», p. 65, Hunter, «Sappho and Latin poetry», pp. 213-225; sobre Catulo: A. Casanova, "Cent anni di papiro per i poeti di Lesbo», en I papiri di Saffo e di Alceo, pp. 1-15, Puglia, Appunti..., p. 15.

57 Ver también Cantos de mujeres, pp. 2, 64, 77, 97, nn. 107, 185, 204.

58 Ver supra; Cantos de mujeres, pp. 97-98.

${ }^{59}$ En época helenística, en indudable coexistencia con ediciones escritas, pues Posidipo habla ya de poemas de Safo en $\sigma \varepsilon \lambda i ́ \delta \varepsilon \varsigma$ escritas, Epigr. 17 Fernández- Galiano y comm. en p. 118.

${ }^{60}$ Poetisa que cantó a Adonis, como también Safo y Nóside: ver A. Bernabé y H. Rodríguez Somolinos, Poetisas griegas, Madrid, 1994, pp. 120-125, 258; Praxila está un tanto olvidada en una parte significativa de la reciente masa de estudios «de género». 
en el que Adonis, moribundo, dice que lo más bello que deja al morir es la

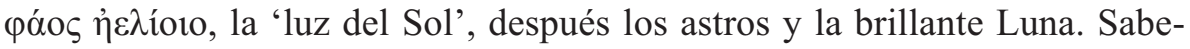
mos que las composiciones de Praxila, como las de Safo, eran cantadas en los banquetes, y se nos ha conservado una escena simposíaca pintada en un vaso en el que puede verse, acompañado por un flautista, a un simposiasta de cuya boca sale la frase $\tilde{\tilde{\omega}} \delta i \grave{\alpha} \tau \tilde{\eta} \varsigma$ $\theta v \rho i ́ \delta o s$, incipit variante de Praxila 8

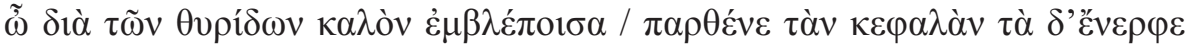
$v v ́ \mu \varphi \alpha$ «oh tú, la que desde la ventana bien miras, virgen en cuanto a tu cabeza, pero mujer casada por abajo». El incipit apunta a un canto de escar-

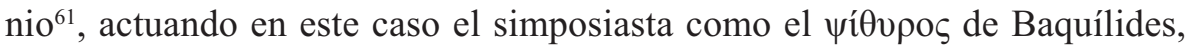

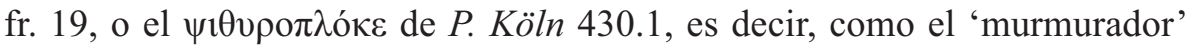
que revela secretos de la vida y amores clandestinos de las mujeres: en el poemilla de Praxila 8 se insinúa que la muchacha que mira por la ventana es doncella sólo aparentemente.

Es difícil ponderar la difusión, no ya en Grecia sino en todo el Mediterráneo, de un canto inscrito e ilustrado en un vaso. Stramaglia ${ }^{62}$ da gran importancia al descubrimiento en Pradejón, junto a Calahorra (La Rioja), de un gran alfar de mediados del siglo I d. C. en el que se han desenterrado numerosísimas piezas cerámicas con representaciones gráficas y escritas, entre las que se encuentra la firma del artista y/o alfarero máximo: Gaius Valerius Verdullus pingit ${ }^{63}$. Las piezas, con inscripciones y dibujos sobreimpresos, es decir, producidas en serie, circulaban de ida y vuelta por la cuenca del Ebro hacia el Mediterráneo e, indudablemente, más allá.

${ }^{61}$ Ver supra en relación con el final del Epodo de Colonia arquiloqueo, vv. 36-40 Merkelbach-West.

${ }^{62}$ A. Stramaglia, «Il fumetto e le sue potencialità mediatiche nel mondo greco latino», en J. A. Fernández Delgado y F. Pordomingo (eds.), Escuela y literatura en Grecia antigua, Cassino, 2007, pp. 577-644, lámina 17.

${ }^{63}$ A. González Blanco y M. Amante Sánchez, «El alfar romano de La Maja (Pradejón, Calahorra-La Rioja) y su importancia en la epigrafía romana y calagurritana», Estrato 3, 1992, pp. 47-54; A. González Blanco, «La epigrafía del Alfar de La Maja», en F. Beltrán Lloris (coord.), El nacimiento de la cultura epigráfica en Occidente (Zaragoza, 1992), Zaragoza, 1995, p. 249; íd. «El alfar de La Maja. Historia de la investigación», Kalakorikos 2, 1997, pp. 9-21; cf. también Stramaglia, «Il fumetto e le sue potencialità mediatiche nel mondo greco latino», p. 604 ss. Muchos de los vasos cerámicos de este alfar (en el que también se producía vidrio) llevan dibujos y epígrafes sobreimpresos, cuyos moldes también se han encontrado. Esta técnica sigillata aparece también en el sur de Francia y en el valle del Ródano. 
Uno de esos vasos, fragmentario, tiene en el borde externo una serie de viñetas, de las que se conservan tres provistas de pequeños textos, a modo de «bocadillos» o frases pronunciados por los personajes representados. En cada una de las dos primeras (I, II, de izquierda a derecha) figura una mujer yaciendo o incorporada en un lecho; en la tercera aparece dibujada una pareja, que ha valido a este vaso el título de «vaso erótico» o «vaso pornográfico».

Son las dos primeras viñetas, fragmentarias, las que aquí nos interesan para el tema de los «cantos de mujer». En la primera, sobre la imagen de la mujer se lee el siguiente texto: basiolu mi da, domine «señor, dame un besillo».

Creemos que en esta y otras breves líneas en las viñetas mencionadas y en otra parte del cuenco se descubren interesantes paralelos con el tipo de poesía que venimos estudiando ${ }^{64}$. Las viñetas han sido interpretadas, bien como un ritual adónico, como cree González Blanco, o como diferentes escenas de un mimo, como opina González-Blanco García ${ }^{65}$. Indudablemente las imágenes y los textos podrían remitir, en último lugar, a cualquiera de las propuestas, si pensamos en los orígenes y difusión que proponíamos para el género que venimos estudiando ${ }^{66}$. Pero, haciendo un análisis filológico-literario del conjunto, pensamos que en las viñetas I y II se escenifica un banquete y/o una cita o citas galantes, como indican los altos lechos, con un escabel al pie, la vajilla, etc., consciente e intencionadamente dibujados. Ciertos detalles nos sitúan en el escenario idóneo de los «cantos de mujeres» en la época helenística: las coronas adornadas con cintas recuerdan aquella con la que el amante de la Farmaceutria en Teócrito 2.121 dice apresurarse para la cita amorosa junto a la Mujer postrada en el lecho por mal de amores; o las que la abandonada mujer del Fragmentum Grenfellianum (Mim. Fr. Pap. 1.25; cf. también la «Monodia por el gladiador», Mim. Fr. Pap. 9.5) manda a su criada tirar ante la evidencia de que el amante no llegará a la cita. En cada viñeta hay un curioso perchero del que pende significativamente una faja o ceñidor

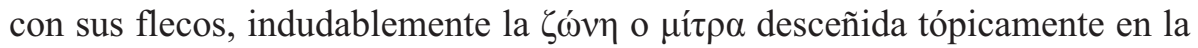

${ }^{64}$ Se ha señalado el carácter métrico de algunos de los textos, M. Mayer, «Epigrafía y paleografía. Una integración difícil», XI Congresso internazionale di epigrafia greca e latina (Roma, 18-24, Sett., 1997), Roma, 1999, I, p. 505.

${ }^{65}$ A. González Blanco, «El alfar romano de La Maja: dimensiones insospechadas», Estrato 7, 1996, p. 59; E. González-Blanco García, «La primera obra de teatro conocida en La Rioja: un mimo del siglo I representado en Calahorra», Kalakorikos 7, 2002, pp. 203-208.

${ }^{66}$ Ver Cantos de mujeres, pp. 24-27 sobre los cantos por Adonis; pp. 119-120 sobre el mimo. 
noche de bodas y en relatos de seducción de doncellas, como en el Oaristus, también de Teócrito 27.55.

Volviendo al minúsculo basiolu mi da domine, de nuestra viñeta I, hay que decir que el tema del beso se prodiga poco en los «cantos de mujeres» griegos antiguos. Sí aparece en uno de sus máximos exponentes, el canto alternado de Aristófanes, Ec. 909-910, cuando la Vieja lanza a su Joven rival una especie de canto/conjuro, en un escenario semejante: «iQue te encuentres una culebra en la cama cuando quieras besar! ${ }^{67}$.

En la misma viñeta I aparece otro texto, variadamente interpretado. Entre las propuestas creemos la más congruente con el próximo basiolu mi da do-

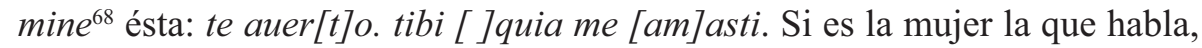
podría traducirse como «Te aborrezco. A ti ... porque me amaste», como una frase desafiante que recuerda el Marissaeum melos (Lyr. Alex. Adesp 5. 2): «Hasta duermo con otro, ¡tanto te quiero!», es decir, irónicamente, «Poco me importas». Si es pronunciado por un hombre, te auer [t]o podría ser la brusca respuesta de éste (¿a la petición conciliatoria del basiolu por parte de la mujer?), significando «me aparto de ti», «te dejo», otro buen trasunto del

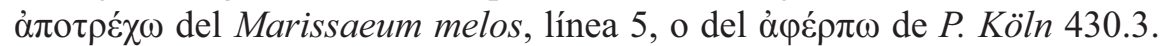

La viñeta II está acompañada también de un texto, menos legible y para el que también se han propuesto variopintas lecturas y traducciones: queremos llamar la atención aquí sólo sobre su comienzo quantu mea senectus, descubriéndose una vez más, en este vaso de la segunda mitad del siglo I d. C., como en la lírica arcaica incluido $P$. Köln 429.1.7, 8, el tema de la ancianidad unido al amoroso.

Pero aún hay más. En la carena del vaso, como commento riepilogativo según dice Stramaglia ${ }^{69}$, aparece la siguiente frase: ]nae ludunt semper uol[u] ptate puellae. Utinam ue $\left[{ }^{70}\right.$. Ello nos hace pensar en un eco de los versos ya mencionados de Ovidio, Fasti 3.676-677, en los que se relata cómo en fies-

${ }^{67}$ Sin embargo se encuentra ya en el «Diálogo Babilónico», $A C M$ 1; será frecuente en la literatura epigramática helenística. El hecho de que la mujer del vaso calagurritano se dirija al amante en vocativo como domine, 'señor', equivale al кúpı propio de estos cantos en época helenística, ver supra n. 34.

${ }^{68}$ E. Ortiz, al pie de una ilustración del vaso en el Catálogo de la exposición Hiberus flumen. El río Ebro y la vida (Zaragoza, 2 de marzo-24 de abril, 1999; M. J. Magaña, coord.), Zaragoza, 1999, p. 346.

69 «Il fumetto e le sue potencialità mediatiche nel mondo greco latino», p. 609.

${ }^{70}$ Hispania epigraphica 7, 1997 (2001), p. 232. 
tas primaverales canent ... obscena puellae ... nam coueunt certaque probra canunt, pasaje relacionado con la casi preceptiva presencia de la ancianidad en la persona de la Vieja Anna Perenna, rejuvenecida en paralelo al mito de Faón. En conmemoración de ese mito, según concluye Ovidio (v. 695), ioci ueteres obscenaque dicta canuntur. Parece difícil, pero la larga ruta que se

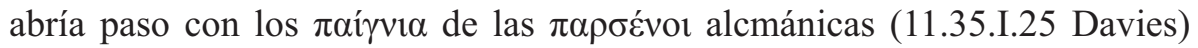
parece alcanzar a los ioci de las puellae ovidianas, y, tal vez, resurgir en las que ludunt semper uol[u]ptate puellae de Calagurris. Son muchos los siglos recorridos, pero aquí no acaba la cosa: en vano entre los siglos VI y IX d. C. la Iglesia tratará de sofocar choreis femineis que entonaban cantica calificados de amatoria, turpia, luxuriosa, amén de diabolica ${ }^{71}$, pero ya prestos a emerger de su casi subterránea corriente como las más antiguas manifestaciones poéticas romances.

Los textos de nuestro vaso calagurritano han sido relacionados con pinturas y graffiti de Pompeya y la frase basiolu mi da domine ha sido considerada «expresión cuasi catulliana» ${ }^{72}$, imaginamos que a causa del multiplicativo $d a$ mi basia mille de Catulo 8.7. Pero es que, además, parece que por el valle del Ebro los basia se prodigaban a mediados del siglo I d. C.: en el severo Thesaurus Linguae Latinae, basium está máximamente documentado en Marcial, natural de Bílbilis (Calatayud), si no en la ribera, sí en la cuenca del Ebro, por la que corrieron poderosas venas literarias y poéticas latinas ${ }^{73}$. Durante mucho tiempo, a lo largo de esa gran vía fluvial que es el Ebro, en

71 Ver en P. Lorenzo Gradín, La canción de mujer en la lírica medieval, Santiago de Compostela, 1990, p. 8 y n. 3, libro que permite una excelente visión general del tema en la Edad Media. Es llamativo, por ejemplo, que en las pastourelles y chansons de toile francesas, aparecen «textos mixtos» narrativos y en estilo directo, notablemente formalizados, siendo introducidos los refrains por fórmulas en las que un joven oye las cuitas de la doncella, (p. 36 ss. y nn.), como en Anacr. 2.11 Page, o P. Köln 430.8. Señala el autor el carácter formalmente «intercalar» o de «inserción» de la canción de mujer en otros poemas o textos diferentes: además del caso, bien conocido, de Cantica Cantabrigensia 14, intercalado entre las estrofas de otro (p. 19 y n. 8), y estudia cantos introducidos en textos en prosa (en romans franceses; al final de varias de las «jornadas» del Decamerón de Bocaccio, o, sorprendentemente, rellenando los espacios en blanco de documentos notariales en Bolonia, pp. 39, 60 s.); no faltan los vituperios al falso y traidor amante (p. 161).

72 Hispania epigraphica 7, p. 232, n. ${ }^{\circ} 590$.

73 Quintiliano nace en Calahorra, de donde viaja a Roma, posiblemente adolescente en años coincidentes con la producción de nuestro vaso. También se ha postulado un eventual origen calagurritano para el poeta Prudencio. 
un sentido y otro, el vaso calagurritano y otros pudieron movilizar «en serie» sus pequeños mensajes, tal vez probra y obscena, como dice Ovidio, pero de repercusiones insospechadas en el espacio y en el tiempo.

\section{Textos romances antiguos}

El zéjel y su derivación la moaxaja, género arábigo-español documentado desde el siglo X, es coincidente en la forma ${ }^{74}$ con la lírica que aflora en el siglo XIII en la Francia del norte (rondeau), Provenza (el virelai), en Galicia, Portugal y Castilla, con la cantiga, el villancico y el laude, y con la ballata en Italia. Y además, creemos ${ }^{75}$ que no hay que desdeñar la influencia que pudieron tener en la cultura árabe, ya desde el Oriente helenizado, formas poéticas como las que hemos expuesto, que incluso permanecieron en el cristianismo.

Ya desde hace bastante tiempo habíamos acudido a las técnicas descritas para las jarchas ${ }^{76}$ y la moaxaja en la poesía hispanoárabe, combinadas entre sí formando un «poema-centauro» ${ }^{77}$, en el que la jarcha, frecuentemente en romance, constituía una especie de pie forzado de toda la moaxaja. Este tipo de composición estrófica era considerado un «invento» de Muccadam de Cabra, según el cual la jarcha podía proceder de la «tradición», ser del propio autor del poema estrófico, o de otros, pudiendo estar en una lengua extranjera, frecuentemente en romance. Ello hace que una y la misma jarcha pueda aparecer al final de moaxajas diferentes, compuestas en árabe (o en hebreo) y en épocas alejadas. Esto, unido también a otros temas que hemos visto, como estar la jarcha en general en boca de mujer, o tópicos recurrentes, como la confidencia a la madre, el amante que huye o no viene, etc., constituye un cúmulo de coincidencias que pueden mantener abiertas las perspectivas que señalábamos hace años.

74 Ver últimamente J. T. Monroe, «Literary hybridization in the Zajal», Journal of Arabic Literature 38, 2007, pp. 324-451.

75 Ver Cantos de mujeres, p. 118 ss. y especialmente n. 233 sobre el alto aprecio (citando a J. Ribera, La música árabe y su influencia en la española, Madrid, 1927 [1985]) por las cantoras griegas y la difusión del mimo en el ámbito árabe desde Oriente a Occidente.

76 Ver E. Gangutia, «Poesía griega de amigo y poesía arábigoespañola», Emerita 49, 1972 , pp. 329-396, y cf. Cantos de mujeres, p. 19 ss.

77 E. García Gómez, «Lírica hispano-árabe y lírica románica», Al Andalus 21, 1956, p. 215, e íd., Las jarchas romances de la serie árabe en su marco, Madrid, 1965 (1990); J. M. Solá Solé, Corpus de poesía mozárabe, Barcelona, 1973. 
Es en ese complejo género arábigo-español donde también se abre ahora camino el pequeño basiolu latín vulgar. Evolucionando a bezyello resurge en una jarcha, compartida en dos moaxajas (n.$^{\text {os }}$ XXIa y b) $)^{78}$ pertenecientes a dos autores distintos, separados por cerca de 200 años. Esta jarcha, puesta en boca de una mujer e introducida con frases totalmente diferentes al final de cada moaxaja: en XXIa es una «encerrada doncellica» la que habla; en XXIb, es una mujer a la que «la ausencia de su amigo ... quita el sueño»):

ya mamma, me-w l-habibe / bays'e no más tornarade. / Gar ke faréyo, ya mamma: / ¿no un bezyello lesarade?

Ay madre, mi amigo / se va y no tornará más. / Dime, qué haré, ay madre / ¿no me dejará [siquiera] un besillo?

Aparecen aquí varios de los elementos que hemos visto hasta ahora: además de la «confidencia a la madre» ${ }^{79}$, encontramos la pregunta «¿qué hacer?» en Safo 58.16 Voigt $+P$. Köln 429.7; la presencia del habib, el 'amigo'

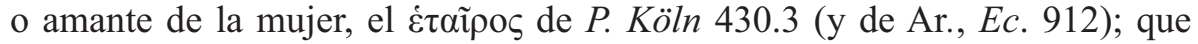

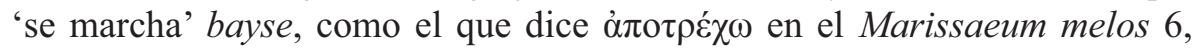

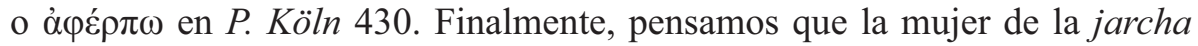
busca la reconciliación con el mismo bezyello < basiolu que la del vaso calagurritano.

El autor de la moaxaja más antigua de las dos, según las semblanzas de los poetas de la colección de moaxajas recopilada por Al-Jatib, es Abu-1-Waled Yunus ibn Isà al Jabbaz Mursí (esto es, «el Murciano»), del siglo XII, del que dice que «no se le conocía asiduidad ni brillantez en la lectura, ni se sabe que frecuentara la enseñanza ${ }^{80}$, es decir, posiblemente se encontraba dentro de una tradición oral, como podría ocurrir también con el famoso poeta llamado el Ciego de Tudela que, junto a otros autores de moaxajas cuyo étnico (p. ej. Saraqustí) aparece unido al nombre, mantuvieron en el valle del Ebro el

\footnotetext{
78 García Gómez, Las jarchas romances..., pp. 195 y 203.

79 Por citar poetas estudiados en Cantos de mujeres: Sapph. 102; Anacr. 2.15, 286.3.1S Page; Ar., Ec. 915; Archipp. 45; Alexis 3; Sophr. 105.

${ }^{80}$ García Gómez, Las jarchas romances..., p. 403. En este género hispano-arábigo no son raras las identificaciones solares: el amante como el alba o como «rayo de sol» (XVII, $\mathrm{XIX);} \mathrm{la} \mathrm{propia} \mathrm{alba} \mathrm{viene} \mathrm{con} \mathrm{fogore} \mathrm{(VII} \mathrm{a,} \mathrm{b).} \mathrm{Protagonismo} \mathrm{solar} \mathrm{ya} \mathrm{en} \mathrm{el} \mathrm{famoso} \mathrm{«can-}$ to de mujer» en latín medieval (ss. X-XI) Foebus abierat subtractis cursibus, Gradín, La canción de mujer, p. 22 y nn. 21-24.
} 
prestigio poético de importantes autores latinos, sin desdeñar el más humilde arte del vaso de Calahorra, no tan lejos de Tudela.

El segundo que utiliza la jarcha del bezyello es Abu Utman ibn Luyun, almeriense activo como poeta en Granada en el siglo XIV. Según García Gómez ${ }^{81}$ es un «rezagado arcaizante» que se sirve de esta jarcha cuando ya el arte de las moaxajas tenía algo de «antigua usanza poética». Pero todo el bagaje poético de los «cantos de mujer», aún convencional en muchos aspectos, y su entorno desde remota antigüedad traspondrán los siglos, por no hablar de milenios, los países, las lenguas, las métricas; aparecerán entre miles de ejemplos de la poesía galaicoportuguesa, de la antigua lírica popular hispánica, insertados en el drama, en la zarzuela, en la copla y el cuplé, en el cine. Tal vez, con la música moderna que prácticamente no se canta ni se aprende oralmente sino que se «descarga» por millones para ser escuchada privadamente con auriculares, estos géneros milenarios estén llegando a su fin.

Fecha de recepción de la primera versión del artículo: 17/09/2009

Fecha de recepción de la versión definitiva del artículo: 16/10/2009 Fecha de aceptación del artículo: 06/10/2009

${ }^{81}$ Las jarchas romances..., p. 405. 